\title{
Thermal test and analysis of concentrator solar cells
}

\author{
Min Cui ${ }^{\mathrm{a}^{*}}$, Nuofu Chen ${ }^{\mathrm{a}, \mathrm{b}}$, Jinliang Wu ${ }^{\mathrm{a}}$, Lei Liu ${ }^{\mathrm{a}}$, Peng Wang ${ }^{\mathrm{a}}$, Yanshuo Wang ${ }^{\mathrm{a}}$, Yiming Bai ${ }^{\mathrm{a}}$ \\ ${ }^{a}$ Key Laboratory of Semiconductor Materials, Institute of Semiconductors, Chinese Academy of \\ Sciences, Beijing 100083, China; \\ ${ }^{b}$ National Laboratory of Microgravity, Institute of Mechanics, Chinese Academy of Sciences, \\ Beijing 100080, China
}

\begin{abstract}
Under high concentration the temperature of photovoltaic solar cells is very high. It is well known that the efficiency and performance of photovoltaic solar cells decrease with the increase of temperature. So cooling is indispensable for a concentrator photovoltaic solar cell at high concentration. Usually passive cooling is widely considered in a concentrator system. However, the thermal conduction principle of concentrator solar cells under passive cooling is seldom reported. In this paper, GaInP/GaAs/Ge triple junction solar cells were fabricated using metal organic chemical vapor deposition technique. The thermal conductivity performance of monolithic concentrator $\mathrm{GaInP} / \mathrm{GaAs} / \mathrm{Ge}$ cascade solar cells under 400X concentration with a heat sink were studied by testing the surface and backside temperatures of solar cells. The tested result shows that temperature difference between both sides of the solar cells is about $1 \mathrm{~K}$. A theoretical model of the thermal conductivity and thermal resistance of the $\mathrm{GaInP} / \mathrm{GaAs} / \mathrm{Ge}$ triple junction solar cells was built, and the calculation temperature difference between both sides of the solar cells is about $0.724 \mathrm{~K}$ which is consistent with the result of practical test. Combining the theoretical model and the practical testing with the upper surface temperature of tested $310 \mathrm{~K}$, the temperature distribution of the solar cells was researched.
\end{abstract}

Keywords: temperature, thermal conductivity, thermal resistance, cooling, concentrator solar cells

\section{INTRODUCTION}

Photovoltaic solar cells under high concentration can get higher efficiency (a typical efficiency value for concentrator solar cells is $40 \%{ }^{[1]}$ ) and lower cost with less expensive concentrating mirrors or lenses ${ }^{[2]}$. Therefore, concentrator solar cells have a promising future for space and terrestrial applications. However when concentration of sunlight gets onto solar cells, only a fraction of concentrated sunlight absorbed by the cells is converted into electrical energy. The larger fraction of concentrated sunlight is converted into thermal energy in the cells which may lead solar cells to high temperatures when with no cooling aids. It is well known that the efficiency of photovoltaic solar cells decrease with the increase of temperature ${ }^{[3]}$. So cooling is indispensable. Most of cases, passive cooling is favored for cost and reliability purpose ${ }^{[4]}$. With a heat sink as passive cooling the large fraction of concentrated sunlight absorbed by the cells will be conducted through the solar cells and then transferred to the ambient by radiation and convection of the heat sink. Then passive cooling is in general use by many concentration systems. However, as the concentrator solar cells themselves under passive cooling, their thermal conduction principle is seldom reported. Therefore, it is very significant to analyze the thermal conduction situation of concentrator solar cells.

In this work, thermal conduction performance of monolithic concentrator $\mathrm{GaInP} / \mathrm{GaAs} / \mathrm{Ge}$ cascade solar cells was studied. Surface and backside temperatures of the solar cells under 400X concentration with a heat sink were tested. A theoretical model of the thermal conductivity and thermal resistance was built, which is consistent with the result of practical test.

\footnotetext{
* Corresponding author. Tel.: +86-10-82304458; fax: +86-10-82304588.

E-mail address: mcui@semi.ac.cn
}

Solid State Lighting and Solar Energy Technologies, edited by Jinmin Li, Yubo Fan,

Ling Wu, Yong-Hang Zhang, Michael E. Coltrin, Yuwen Zhao, Nuofu Chen, Vladimir M. Andreev, Jai Singh, Proc. of SPIE Vol. 6841, 684117, (2007) · 0277-786X/07/\$18 · doi: 10.1117/12.755323 


\section{FABRICATION OF CASCADE SOLAR CELLS}

$\mathrm{GaInP} / \mathrm{GaAs} / \mathrm{Ge}$ triple junction solar cells $(3 \mathrm{~mm} \times 3 \mathrm{~mm})$ for this study were grown on p-type Ge substrate using metal organic chemical vapor deposition (MOCVD) technique. Fig.1 shows a schematic illustration of the GaInP/GaAs/Ge triple junction cell fabricated in this study. As shown in Fig.1 the thicknesses of GaInP solar cell, GaAs solar cell and Ge substrate (including Ge solar cell) are $0.7 \mu \mathrm{m}, 4 \mu \mathrm{m}$ and $200 \mu \mathrm{m}$, respectively.

\begin{tabular}{|c|c|c|}
\hline & $N$ metal & \\
\hline $\mathrm{AR}$ & $\mathrm{N}+\mathrm{GaAs}$ & \\
\hline \multicolumn{3}{|c|}{ GalnP cell $(0.7 \mu \mathrm{m})$} \\
\hline \multicolumn{3}{|c|}{ Tunnel Junction } \\
\hline \multicolumn{3}{|c|}{ GaAs cell $(4 \mu \mathrm{m})$} \\
\hline \multicolumn{3}{|c|}{ Tunnel Junction } \\
\hline \multicolumn{3}{|c|}{ Ge cell } \\
\hline \multicolumn{3}{|c|}{ P Ge substrate $(200 \mu \mathrm{m})$} \\
\hline & metal & \\
\hline
\end{tabular}

Fig. 1. The schematic illustration of the $\mathrm{GaInP} / \mathrm{GaAs} / \mathrm{Ge}$ triple junction cell fabricated in this study

\section{TEMPERATURE TESTING}

The temperatures of $\mathrm{GaInP} / \mathrm{GaAs} / \mathrm{Ge}$ cascade solar cells under $400 \mathrm{X}$ concentration with a heat sink were tested outside. Experiment time was chosen at noon with thin clouds and weak winds. Temperatures of the upper surface and the backside of the cascade solar cells were tested by two sheet temperature sensor Pt100 with the accuracy of $1 \mathrm{~K}$. The solar cells were being tracked with the sun during the tested course. Fig. 2 shows the temperature testing results of the solar cells with time continuing, where T1 is the temperature of the upper surface of the solar cells and T4 is the temperature of the backside of the solar cells. Because test was carried out in the out door, clouds and winds could not being ignored so that there is some fluctuation of temperatures in Fig. 2. However, from Fig. 2 we can see that with time continuing the temperature difference between both sides of the solar cells is about $1 \mathrm{~K}$, and T1 is maintaining at about $310 \mathrm{~K}$.

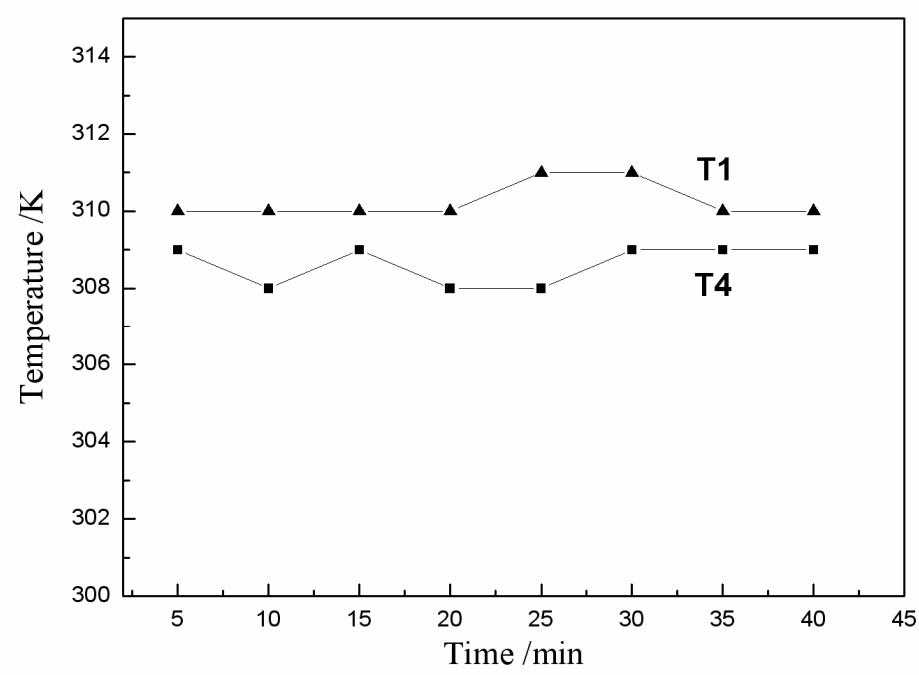

Fig. 2. Temperature testing results of the solar cells 


\section{THERMAL CONDUCTION THEORETICAL MODEL}

\subsection{One-dimensional conduction and thermal resistances}

Thermal diffusion through solids is governed by Fourier's law, which in one-dimensional form is expressed as

$$
Q=-\lambda A \frac{d T}{d x}
$$

where $Q$ is the heat current, $\lambda$ is the thermal conductivity of the medium, $A$ is the cross-sectional area for heat flow, and $d T / d x$ is the temperature gradient, which, because it is negative, requires insertion of the minus sign in equation (1) to assure a positive heat flow $Q^{[5]}$. For a monolayer plane wall with a temperature difference between the two sides, the heat transfer by conduction is shown in Fig. 3, where $T 1$ is the higher temperature of the upper side, $T 2$ is the lower temperature of the bottom side $(T 1>T 2)$, and $d$ is the thickness of the plane wall.

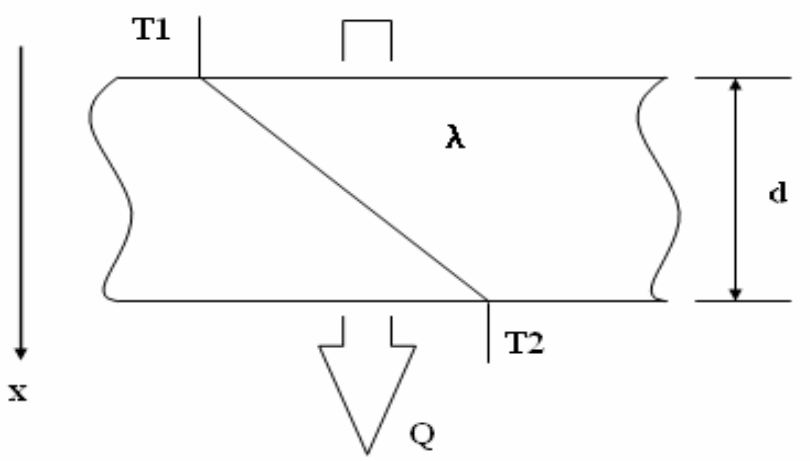

Fig. 3. Heat transfer by conduction of a monolayer plane wall

In the Fig. 3 the heat $Q$ diffuses from $T 1$ side to $T 2$ side. In the steady-state, $Q$ is a constant at random cross-section. Assuming the monolayer plane wall is uniform, the thermal conductivity $\lambda$ is a constant with no dependence on temperature. So

$$
d T=-\frac{Q}{\lambda A} d x
$$

where $-\frac{Q}{\lambda A}$ is a constant. Then the integration of equation (2) is shown as

$$
\int_{T 1}^{T 2} d T=-\frac{Q}{\lambda A} \int_{0}^{d} d x
$$

So the integration result is

$$
Q=\frac{\lambda A}{d}(T 1-T 2)=\frac{\Delta T}{d / \lambda A}
$$

where $\Delta T$ is the temperature difference between the two sides of monolayer plane wall.

The form of equation (4) suggests that in a way that is analogous to Ohm's law governing electrical current flow through a resistance, then it is possible to define a conduction thermal resistance as

$$
\begin{gathered}
R=\frac{T 1-T 2}{Q}=\frac{\Delta T}{Q}=\frac{d}{\lambda A} \\
Q=\frac{\Delta T}{R}
\end{gathered}
$$




\subsection{Theoretical model of GaInP/GaAs/Ge cascade solar cells}

Because of the closely packed set of the GaInP/GaAs/Ge cascade solar cells where heat flow is primarily directed in the normal direction ${ }^{[6]}$, the above one-dimensional thermal model was used in this work. In this model the heat analyses of tunnel junction and metal layer were ignored. A schematic illustration of the heat flow of the $\mathrm{GaInP} / \mathrm{GaAs} / \mathrm{Ge}$ triple junction cell is shown in Fig.4,

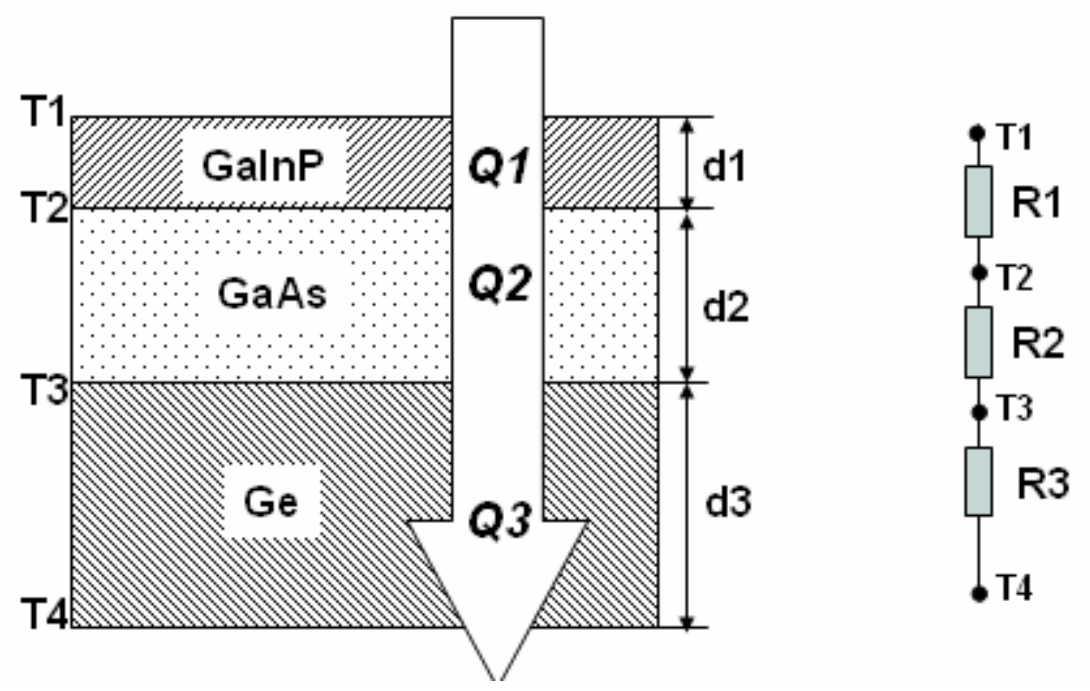

Fig. 4. Schematic illustration of the heat flow of the GaInP/GaAs/Ge triple junction cell

where $T 1, T 2, T 3$ and $T 4$ are temperatures of each layer of the solar cells, $d 1, d 2$ and $d 3$ are thicknesses of GaInP solar cell, GaAs solar cell and Ge substrate (including Ge solar cell), respectively, $R 1, R 2$ and $R 3$ are the thermal resistances of GaInP solar cell, GaAs solar cell and Ge substrate (including Ge solar cell), Q1, Q2 and $Q 3$ are the heat current of each solar cells.

According to one-dimensional conduction model, $Q 1, Q 2$ and $Q 3$ were expressed as

$$
\begin{gathered}
Q 1=\frac{T 1-T 2}{R 1}, \quad T 1-T 2=Q 1 \times R 1 \\
Q 2=\frac{T 2-T 3}{R 2}, \quad T 2-T 3=Q 2 \times R 2 \\
Q 3=\frac{T 3-T 4}{R 3}, \quad T 3-T 4=Q 3 \times R 3
\end{gathered}
$$

In the steady-state,

$$
Q 1=Q 2=Q 3=Q
$$

From the above equations $Q$ was calculated as

$$
Q=\frac{(T 1-T 2)+(T 2-T 3)+(T 3-T 4)}{R 1+R 2+R 3}=\frac{T 1-T 4}{R 1+R 2+R 3} .
$$

\section{RESULTS AND DISCUSSIONS}

\subsection{Theoretical calculation of temperatures}

The situation of $\mathrm{GaInP} / \mathrm{GaAs} / \mathrm{Ge}$ cascade solar cells under $400 \mathrm{X}$ concentration with a heat sink was considered in the calculation. According to the energy conservation the heat current of conduction $Q$ is equal to 


$$
Q=Q_{\text {total }}-Q_{e}
$$

where $Q_{\text {total }}$ is the sunlight energy absorbed by the cells, and $Q_{e}$ the electric energy converted by solar cells. The heat energy produced in the inner of solar cells and the radiation energy of the surface of the solar cells were ignored in this work.

Considering the transmissivity of the lens and the absorptivity of the solar cell surface, $Q_{\text {total }}$ should be as

$$
Q_{\text {total }}=\tau \alpha A_{0} C q_{0}
$$

where $\tau$ is the transmissivity of the lens (in this work $\tau$ is taken as 0.85 ), $C$ is the concentration ratio (in this work $C=400$ ), $\alpha$ is the absorptivity of solar cells surface (in this work $\alpha$ is taken as 0.85), $q_{0}$ is the energy density of AM1.5 $\left(q_{0}=1 \mathrm{~kW} / \mathrm{m}^{2}\right)$, and $A_{0}$ is the area of solar cells $\left(A_{0}=3 \mathrm{~mm} \times 3 \mathrm{~mm}\right)$. The electric energy converted by solar cells $Q_{e}$ is

$$
Q_{e}=\eta Q_{\text {total }}
$$

Where $\eta$ is the conversion efficiency of photovoltaic solar cells (for our concentrator cascade solar cells $\eta$ is $30 \%$ ).

According to equations (11-14), where $R 1$ is the thermal resistance of GaInP solar cells with thermal resistivity of $19 \mathrm{~cm} \cdot \mathrm{K} / \mathrm{W}^{[7]}, R 2$ is the thermal resistance of GaAs solar cells with thermal conductivity $\lambda 2 \mathrm{of} 46 \mathrm{~W} /(\mathrm{m} \cdot \mathrm{K})^{[8]}$, and $\mathrm{R} 3$ is the thermal resistance of Ge with thermal conductivity $\lambda 3$ of $60 \mathrm{~W} /(\mathrm{m} \cdot \mathrm{K})^{[9]}$, wherein these thermal values are at $300 \mathrm{~K}$, the temperature difference between both sides of the solar cells $\Delta \mathrm{T}$ (T1-T4) is about $0.724 \mathrm{~K}$.

From the above calculation, we can see that theoretical result of temperature difference $(0.724 \mathrm{~K})$ is consistent with the result of practical test $(1 \mathrm{~K})$. The little difference between theoretical result and practical result may come from the accuracy of the temperature sensor, or may come from practical situation of tunnel junction and metal layer's conduction and the cases of being non-uniform of the solar cells' layers.

\subsection{Comprehensive discussions}

Combining the theoretical model and the practical testing, $T 1$ with the average value $310 \mathrm{~K}$ was used in the calculation model. From equations of (7-14) the following temperatures of $T 2, T 3$ and $T 4$ were calculated as $309.973 \mathrm{~K}, 309.949 \mathrm{~K}$ and 309.276K, respectively. The temperature gradient was detailed shown in Fig.5.

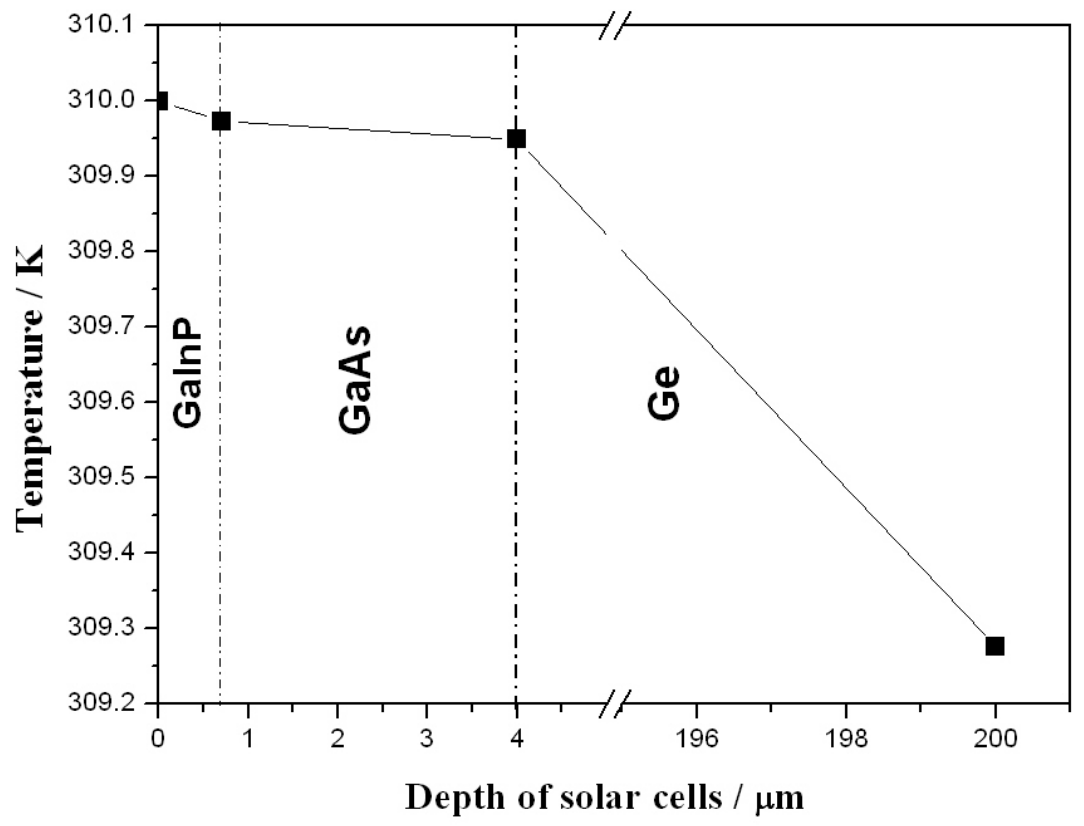

Fig. 5. Temperature distribution of the solar cells 
From Fig. 5 we can see that temperature mainly falls down in Ge substrate, because sub-solar cells are much thinner than the substrate. We can also see that the slope of the lines in the Fig. 5 increase with the increase of thermal conductivity of the materials.

\section{CONCLUSIONS}

$\mathrm{GaInP} / \mathrm{GaAs} / \mathrm{Ge}$ triple junction solar cells $(3 \mathrm{~mm} \times 3 \mathrm{~mm})$ were grown on $\mathrm{p}$-type Ge substrate using metal organic chemical vapor deposition (MOCVD) technique. The upper surface and backside temperatures of $\mathrm{GaInP} / \mathrm{GaAs} / \mathrm{Ge}$ solar cells under 400X concentration with a heat sink were tested outdoor at noon, which showed that the temperature difference between both sides of the solar cells is about 1K. One-dimensional conduction of Fourier's law was studied for the thermal conduction model. Thermal resistance was also introduced for analysis of the heat conduction. Heat conduction of the triple junction solar cells under $400 \mathrm{X}$ concentration with a heat sink was explored by the model. The result of the model showed that the calculation temperature difference between both sides of the solar cells was about $0.724 \mathrm{~K}$, which approaches to the practical tested result. Combining the theoretical model and the practical testing with the upper surface temperature of tested $310 \mathrm{~K}$, the temperature distribution of the solar cells was researched.

\section{REFERENCES}

1 R.R. King, D.C. Law, K.M. Edmondson, C.M. Fetzer, G.S. Kinsey, H. Yoon, R.A. Sherif, N.H. Karam, " $40 \%$ efficient metamorphic GaInP/GaInAs/Ge multijunction solar cells”, Applied Physics Letters, 90, (183516), 2007.

2 Anja Royne, Christopher J. Dey, David R. Mills, "Cooling of photovoltaic cells under concentrated illumination: a critical review”, Solar Energy Materials \& Solar Cells, 86, (451-483), 2005.

3 David Meneses-Rodriguez, Paul P. Horley, Jesus Gonzalez-Hernandez, Yuri V. Vorobiev, Peter N. Gorley, "Photovoltaic solar cells performance at elevated temperatures", Solar Energy, 78, (243-250), 2005.

4 Araki K, Uozumi H, Yamaguchi M, "A simple passive cooling structure and its heat analysis for 500X concentrator PV module", 29th IEEE PVSC, New Orleans, (1568-1571), 2002.

5 Adrian Bejan, Allan D.Kraus, Heat transfer handbook, John Wiley \& Sons, Inc., 2003.

6 Anja Royne, Christopher J. Dey, David R. Mills, "Cooling of photovoltaic cells under concentrated illumination: a critical review", Solar Energy Materials \& Solar Cells, 86, (455-456), 2005.

7 Characteristics and Properties of New Semiconductor Materials, electronic archive of Ioffe physico-technical Institute, Russian Federation, 2001.

8 S. Tiwari, Compound Semiconductor Device Physics, Academic Press, 1992.

9 K. Ng, Complete Guide to Semiconductor Devices, McGraw-Hill, 1995. 